\title{
SISTEM PENDUKUNG KEPUTUSAN PENENTUAN CALON PENERIMA BEASISWA MENGGUNAKAN METODE FUZZY DATABASE MODEL TAHANI
}

\author{
Ardi Sanjaya \\ Fakultas Teknik, Program Studi Teknik Informatika \\ Universitas Nusantara PGRI Kediri \\ Email: dersky@gmail.com \\ Risaniatin Ningsih \\ Fakultas Ilmu Kependidikan dan Keguruan, Program Studi Bimbingan dan Konseling \\ Universitas Nusantara PGRI Kediri \\ Email: risadyne@gmail.com
}

\begin{abstract}
ABSTRAK
Pada penelitian ini dibuat suatu sistem informasi berupa pendukung keputusan untuk menentukan calon penerima beasiswa menggunakan metode fuzzy database model Tahani. Penelitian ini dilakukan pada Sekolah Menengah Kejuruan (SMK) PGRI 4 Kota Kediri. Tujuan dari penelitian ini adalah untuk publikasi ilmiah dan untuk pembuatan sistem guna memberikan suatu pendukung keputusan berupa pengurutan data siswa berdasar kriteria tertentu sebagai prioritas untuk menerima beasiswa. Dengan memanfaatkan database siswa yang ada seperti data penghasilan orang tua, data prestasi, data jarak rumah kesekolah, dan sejenisnya, maka pihak sekolah akan lebih mudah untuk mengolah data siswa dalam memilih calon-calon penerima beasiswa dengan menggunakan sistem pendukung keputusan ini. Jika hanya menggunakan database standar akan kesulitan untuk menentukan calon-calon penerima beasiswa sebab pada database standar bersifat pasti, deterministik dan presisi. Namun pada kenyataannya pengolahan data yang ada lebih bersifat samar (fuzzy). Misalnya kriteria jarak rumah yang dikategorikan dekat, sedang dan jauh. Sedangkan pada database data jarak rumah berisi nilai pasti. Hasil dari penelitian ini adalah telah berhasil dibuat suatu sistem informasi pengolahan data siswa sebagai pendukung keputusan penentuan calon penerima beasiswa. Informasi yang dihasilkan salah satunya adalah urutan prioritas calon penerima beasiswa sehingga proses penentuan calon penerima beasiswa diharapkan dapat dikerjakan lebih efektif dan efisien.
\end{abstract}

Kata kunci: sistem pendukung keputusan, fuzzy database model tahani.

\begin{abstract}
In this study, a decision support system in the form of information to determine the scholarship recipients using fuzzy Tahani model database. This study will be conducted at the Vocational High School PGRI 4 Kediri. The purpose of this study was to scientific publications and to manufacture a system to provide decision support in the form of student data sorting based on certain criteria as a priority to receive a scholarship. By utilizing the existing student database as parental income data, achievement data, the data within the home to school, and the like, then the school will be easier to process student data in selecting candidates for scholarship recipients to use this decision support system. If you only use standard database will be difficult to determine the prospective grantee because the standard database is uncertain, deterministic and precision. But in facts the data processing that is more vagues (fuzzy). For the example the distance criteria categorized houses near, medium and far. While in the home range data database contains exact value. Information generated one of which is the priority order of the applicants so that the process of determining the scholarship recipients are expected to be done more effectively and efficiently.
\end{abstract}

Keywords: decision support systems, fuzzy database model tahani.

\section{PENDAHULUAN}

Seiring dengan perkembangan teknologi, beberapa pekerjaan manusia dapat menjadi lebih mudah dengan bantuan teknologi komputer seperti dalam hal mengolah data. Dengan bantuan komputer, data yang diolah akan lebih efektif dan efisien untuk menghasilkan informasi yang diinginkan. Data merupakan fakta yang dapat disimpan dan memiliki arti [1]. Misalnya pada data siswa, terdapat nama, alamat, jarak dari rumah ke sekolah, nama orang tua, penghasilan orang tua dan lain-lain. Data dari siswa dikumpulkan menjadi satu atau terpusat dan disebut dengan basis data (database). Data yang dikonsumsi 
oleh pihak diluar organisasi tentunya sudah diolah dan tidak disajikan dalam bentuk mentah. Namun harus diolah terlebih dahulu agar lebih efektif dan efisien. Hasil dari pengolahan data disebut dengan informasi. Salah satu contohnya adalah mengolah data siswa untuk menentukan daftar calon penerima beasiswa berdasarkan kriteria tertentu dari suatu database siswa.

Sekolah Menengah Kejuruan (SMK) PGRI 4 Kediri merupakan sekolah dengan 3 program studi yaitu Teknik Mesin, Teknik Sepeda Motor dan Teknik Komputer Jaringan. Salah satu kendala yang dihadapi pihak tata usaha adalah kesulitan dalam menentukan calon penerima beasiswa dikarenakan selama ini masih dilakukan secara manual.

Salah satu metode yang bisa digunakan untuk mengolah database agar menghasilkan informasi seperti penentuan calon penerima beasiswa adalah menggunakan metode fuzzy database model Tahani. Dengan menggunakan relasi yang ada pada database serta penekanan fuzzy pada beberapa field dalam tabel yang dijadikan kriteria akan menghasilkan informasi yang diinginkan.

Salah satu permasalahan kesulitan penentuan calon penerima beasiswa pada SMK PGRI 4 Kediri dapat diatasi dengan motode fuzzy database model Tahani. Data siswa yang bersifat fuzzy seperti kriteria jarak rumah jauh-dekat, pengahsilan orang tua rendah-tinggi dan sejenisnya dapat diolah menghasilkan nilai yang bersifat pasti sehingga akan lebih mudah dalam perhitungan untuk menentukan prioritas yang disajikan dalam daftar calon penerima beasiswa.

\subsection{Rumusan Masalah}

Rumusan masalah pada penelitian ini adalah bagaimana membuat sebuah sistem informasi yang dapat menentukan calon penerima beasiswa menggunakan metode fuzzy tahani model database ?

\subsection{Batasan Masalah}

Pada penelitian ini ditetapkan beberapa hal yang menjadi batasan masalah diantaranya adalah sebagai berikut:

1) Penelitian akan dilakukan pada siswa SMK PGRI 4 kota Kediri.

2) Pengambilan data dilakukan pada siswa tahun pelajaran $2015 / 2016$.

3) Metode yang digunakan adalah fuzzy tahani model database.

4) Bahasa pemrograman yang digunakan adalah PHP dan database MySql.

5) Kriteria penentuan calon penerima beasiswa adalah penghasilan wali murid, peingkat kelas, ketidakhadiran, catatan BP dan uang saku.

6) Output dari sistem berupa daftar urutan calon penerima beasiswa.

\subsection{Tujuan Penelitian}

Adapun tujuan dilakukannya penelitian ini adalah untuk membuat sistem informasi untuk menentukan calon penerima beasiswa pada SMK PGRI 4 kota Kediri.

\subsection{Landasan Teori}

\subsubsection{Basis Data}

Data merupakan representasi dari fakta atau gambaran mengenai suatu obyek atau kejadian [2]. Data dinyatakan dengan nilai dalam bentuk angka, deretan karakter atau simbol. Misalnya fakta atau kenyataan tentang biodata siswa seperti nama lengkap, alamat, nama orang tua dan lain-lain. Contoh lain dari fakta mengenai kejadian atau peristiwa misalnya adalah transaksi penjualan online yang meliputi data waktu, penjual, pembeli, nilai transaksi dan lain-lain.

Basis data (database) adalah cara mendokumentasikan berbagai macam data yang kemudian dimanajemen dengan sebuah sistem untuk kemudian disimpan dalam sebuah media penyimpanan [3]. Dalam basis data, data yang ada tidak hanya sekedar diletakkan dan disimpan begitu saja dalam sebuah media penyimpanan, akan tetapi dikelola dengan sistem pengaturan tertentu. Dengan demikian, data dengan jumlah besar dan kompleks dapat tersusun sangat baik sehingga memungkinkan pengaksesan data dengan mudah dan cepat oleh pengguna. Basis data juga bisa diartikan sekumpulan informasi yang sangat komplek. Ilustrasi hubungan basis data dan komputer pengguna disajikan pada gambar 1 berikut: 


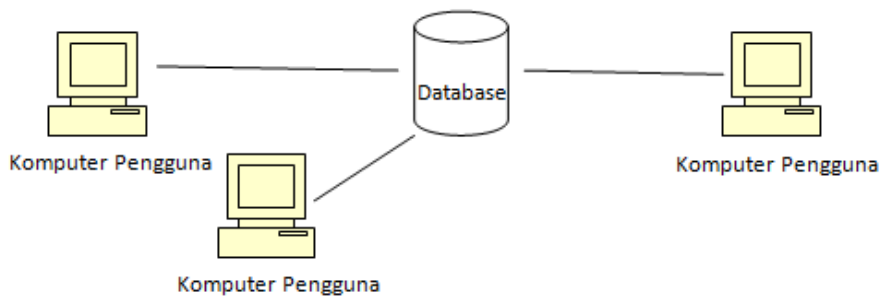

\section{Gambar 1. Ilustrasi Hubungan Basis Data Dan Komputer Pengguna}

\subsubsection{Fuzzy Tahani}

Logika fuzzy merupakan salah satu komponen pembentuk soft computing. Logika fuzzy pertama kali diperkenalkan oleh Prof. Lotfi A. Zadeh pada tahun 1965. Dasar logika fuzzy adalah teori himpunan fuzzy. Pada teori himpunan fuzzy, peranan derajat keanggotaan sebagai penentu keberadaan elemen dalam suatu himpunan sangatlah penting. Nilai keanggotaan atau derajat keanggotaan menjadi ciri utama dari penalaran dengan logika fuzzy tersebut. Dalam banyak hal, logika fuzzy digunakan sebagai suatu cara untuk memetakan permasalahan dari input menuju ke output yang diharapkan [4]. Fuzzy Decission Support System (FDSS) menggunakan dasar pengetahuan dalam bentuk "if-then" untuk memproses informasi [5]. Metode fussy yang sesuai untuk mengolah informasi pada database (basis data) yaitu fuzzy database model Tahani [6].

Fuzzy database adalah basis data mempunyai kemampuan untuk menyimpan dan memanipulasi data-data yang mengandung ketidakpastian secara langsung. Artinya, pengguna memasukkan informasiinformasi yang mengandung unsur kekaburan ke dalam pangkalan data. Basis data jenis ini juga didukung oleh query yang bersifat fuzzy untuk memperoleh informasi [7].

Sistem basis data fuzzy merupakan salah satu metode fuzzy yang menggunakan basis data standar. Pada basis data standar, data diklasifikasikan berdasarkan bagaimana data tersebut dipandang oleh user. Oleh karena itu, pada basis data standar data yang ditampilkan akan keluar seperti data yang telah disimpan. Namun kenyataannya, seseorang terkadang membutuhkan informasi dari data-data yang bersifat ambiguous. Sedangkan pada sistem basis data standar data yang ditampilkan tidak dapat menampilkan data yang ambiguous. Oleh karena itu, apabila hal ini terjadi, maka sebaiknya digunakan sistem basis data fuzzy [8].

Dengan menggunakan database standar, kita dapat mencari data-data dengan spesifikasi tertentu dengan menggunakan query. Misal kita ingin mendapatkan informasi tentang nama-nama karyawan yang usianya kurang dari 35 tahun. Contoh data yang digunakan tersaji pada tabel 1, maka kita bisa ciptakan suatu query:

Select Nama Form Karyawan Where (Umur <35)

Tabel 1. Contoh data karyawan

\begin{tabular}{ccccc}
\hline Nip & Nama & Umur & Thn Masuk & Gaji \\
\hline 01 & Lia & 30 & 1996 & 750.000 \\
02 & Iwan & 48 & 1985 & 1.500 .000 \\
03 & Sari & 36 & 1988 & 1.255 .000 \\
04 & Andi & 37 & 1998 & 1.040 .000 \\
05 & Budi & 42 & 1990 & 950.000 \\
06 & Amir & 39 & 1989 & 1.600 .000 \\
07 & Rian & 37 & 1997 & 1.250 .000 \\
08 & Kiki & 32 & 2001 & 550.000 \\
09 & Alda & 35 & 1999 & 735.000 \\
10 & Yoga & 25 & 2000 & 860.000 \\
\hline
\end{tabular}

Sehingga muncul nama-nama Lia, Kiki, dan Yoga. Namun seseorang terkadang membutuhkan informasi dari data-data yang bersifat ambiguous. Apabila hal ini terjadi, maka bisa digunakan basis data Fuzzy [9]. Fungis keanggotaan untuk variabel usia diilustrasikan pada gambar 2 sebagai berikut: 


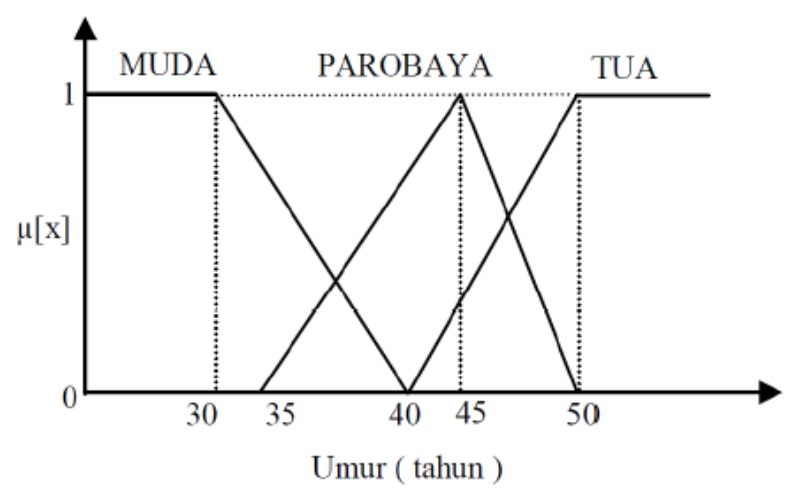

Gambar 2. Fungsi Keanggotaan untuk Variabel Usia

Untuk penentuan nilai derajat keanggotaan muda, bisa menggunakan persamaan 1 atau 2 atau 3 . Untuk penentuan nilai derajat keanggotaan parobaya menggunakan persamaan 4 atau 5 atau 6 , sedangkan untuk menentukan derajat keanggotaan tua menggunakan persamaan 7 atau 8 atau 9 sebagai berikut:

$$
\begin{aligned}
& \mu \text { Muda [x] }\left\{\begin{array}{cc}
1 & x<30 \\
(40-x) / 10 & 30 \leq x \leq 40 \\
0 & x>40
\end{array}\right. \\
& \mu \text { Parobaya [x] }\left\{\begin{array}{cc}
0 & x<30 \text { atau } x>50 \\
(x-35) / 10 & 35 \leq x \leq 45 \\
(50-x) / 5 & 45 \leq x \leq 50
\end{array}\right. \\
& \mu \text { Tua [x] }\left\{\begin{array}{cc}
0 & x<40 \\
(x-40) / 10 & 40 \leq x \leq 50 \\
1 & x>50
\end{array}\right.
\end{aligned}
$$

Berdasarkan pengolahan fungsi keanggotaan untuk variabel usia dengan derajat keanggotaan muda, parobaya dan tua didapat hasil seperti disajikan pada tabel 2 berikut:

Tabel 2. Tabel karyawan berdasarkan umur

\begin{tabular}{clcccc}
\hline \multirow{2}{*}{ Nip } & \multirow{2}{*}{ Nama } & \multirow{2}{*}{ Umur } & \multicolumn{3}{c}{ Derajat Keanggotaan $[\boldsymbol{x}]$} \\
& & & Muda & Parobaya & Tua \\
\hline 01 & Lia & 30 & 1 & 0 & 0 \\
02 & Iwan & 48 & 0 & 0,4 & 0,8 \\
03 & Sari & 36 & 0,4 & 0,1 & 0 \\
04 & Andi & 37 & 0,3 & 0,2 & 0 \\
05 & Budi & 42 & 0 & 0,7 & 0,2 \\
06 & Amir & 39 & 0,1 & 0,4 & 0 \\
07 & Rian & 37 & 0,3 & 0,2 & 0 \\
08 & Kiki & 32 & 0,8 & 0 & 0 \\
09 & Alda & 35 & 0,5 & 0 & 0 \\
10 & Yoga & 25 & 1 & 0 & 0 \\
\hline
\end{tabular}

Ada beberapa query yang dapat diberikan untuk menggali informasi lainnya, misalnya: Siapa sajakah karyawan yang masih muda tapi memiliki gaji tinggi ?. Kita bisa menggunakan query di bawah ini dan dari hasil query tersebut didapatkan hasil seperti tersaji pada tabel 3. 
Tabel 3. Data Karyawan yang masih muda dan memiliki gaji tinggi

\begin{tabular}{ccccccc}
\hline \multirow{2}{*}{ Nip } & \multirow{2}{*}{ Nama } & \multirow{2}{*}{ Umur } & $\begin{array}{c}\text { Gaji/Bln } \\
(\boldsymbol{R} \boldsymbol{p})\end{array}$ & \multicolumn{3}{c}{ Derajat Keanggotaan $[\boldsymbol{x}]$} \\
& & & Parobaya & Tua \\
\hline 03 & Sari & 36 & 1.255 .000 & 0,4 & 0,1 & 0 \\
07 & Rian & 37 & 1.250 .000 & 0,3 & 0,2 & 0 \\
06 & Amir & 39 & 1.600 .000 & 0,1 & 0,4 & 0 \\
04 & Andi & 37 & 1.040 .000 & 0,3 & 0,2 & 0 \\
01 & Lia & 30 & 750.000 & 1 & 0 & 0 \\
02 & Iwan & 48 & 1.500 .000 & 0 & 0,4 & 0,8 \\
05 & Budi & 42 & 950.000 & 0 & 0,7 & 0,2 \\
08 & Kiki & 32 & 550.000 & 0,8 & 0 & 0 \\
09 & Alda & 35 & 735.000 & 0,5 & 0 & 0 \\
10 & Yoga & 25 & 860.000 & 1 & 0 & 0 \\
\hline
\end{tabular}

Dari tabel 3 dapat dilihat bahwa karyawan yang masih muda dan memiliki gaji yang tinggi adalah Sari.

\section{METODOLOGI PENELITIAN}

Dalam pembuatan sistem pendukung keputusan penentuan calon penerima beasiswa pada SMK PGRI 4 Kediri, diperlukan diagram konteks seperti tersaji pada gambar 3. Entitas administrator memasukkan data berupa data siswa, data pengguna dan data kriteria.

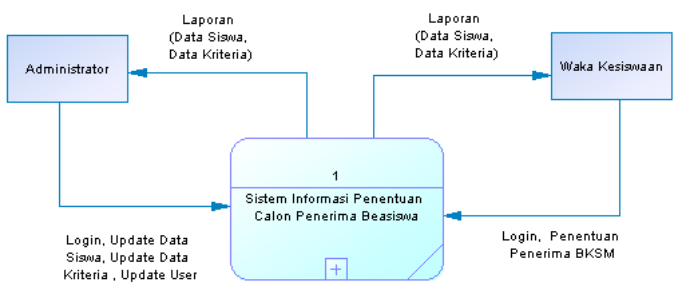

Gambar 3. Diagram Konteks Dari Sistem Yang Akan Dibuat

Untuk rancangan model tabel disajikan pada gambar 4 sebagai berikut :

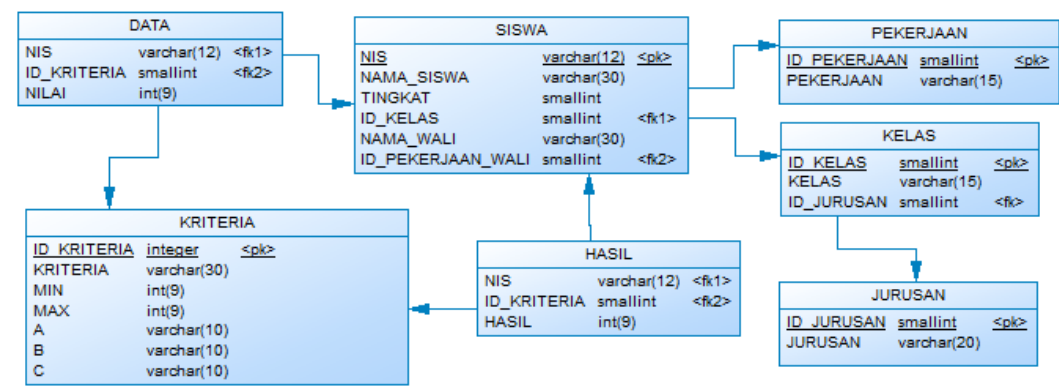

Gambar 4. Rancangan Model Tabel Dan Relasinya

Data yang digunakan untuk uji coba menggunakan data siswa dari 1 kelas yaitu tingkat 1 kelas TKJ 1 dengan jumlah siswa sebanyak 52. Data tersaji pada tabel 4 sebagai berikut :

Tabel 4. Data siswa

\begin{tabular}{cccccc}
\hline NIS & $\begin{array}{c}\text { Penghasilan } \\
\text { Wali Murid }\end{array}$ & $\begin{array}{c}\text { Peringkat } \\
\text { Kelas }\end{array}$ & Ketidakhadiran & Catatan BP & $\begin{array}{c}\text { Uang } \\
\text { Saku }\end{array}$ \\
\hline 111535 & 800000 & 3 & 0 & 0 & 0 \\
111027 & 1000000 & 39 & 0 & 0 & 0 \\
111525 & 1000000 & 4 & 0 & 0 & 1000 \\
111526 & 1000000 & 35 & 0 & 0 & 0 \\
111528 & 1000000 & 26 & 0 & 0 & 0 \\
\hline
\end{tabular}




\begin{tabular}{|c|c|c|c|c|c|}
\hline$N I S$ & $\begin{array}{c}\text { Penghasilan } \\
\text { Wali Murid }\end{array}$ & $\begin{array}{c}\text { Peringkat } \\
\text { Kelas }\end{array}$ & Ketidakhadiran & Catatan BP & $\begin{array}{l}\text { Uang } \\
\text { Saku }\end{array}$ \\
\hline 111529 & 1000000 & 10 & 0 & 0 & 0 \\
\hline 111531 & 1000000 & 41 & 1 & 0 & 0 \\
\hline 111532 & 1000000 & 30 & 1 & 0 & 0 \\
\hline 111533 & 1000000 & 9 & 1 & 0 & 0 \\
\hline 111538 & 1000000 & 2 & 0 & 0 & 0 \\
\hline 111543 & 1000000 & 22 & 1 & 0 & 0 \\
\hline 111544 & 1000000 & 13 & 0 & 0 & 0 \\
\hline 111546 & 1000000 & 36 & 1 & 0 & 0 \\
\hline 111548 & 1000000 & 24 & 0 & 0 & 1000 \\
\hline 111549 & 1000000 & 51 & 1 & 0 & 0 \\
\hline 111553 & 1000000 & 34 & 0 & 0 & 0 \\
\hline 111554 & 1000000 & 15 & 0 & 0 & 0 \\
\hline 111555 & 1000000 & 12 & 1 & 0 & 0 \\
\hline 111557 & 1000000 & 17 & 0 & 0 & 0 \\
\hline 111558 & 1000000 & 29 & 1 & 0 & 0 \\
\hline 111563 & 1000000 & 8 & 0 & 0 & 0 \\
\hline 111564 & 1000000 & 33 & 0 & 0 & 0 \\
\hline 111565 & 1000000 & 40 & 1 & 0 & 1000 \\
\hline 111567 & 1000000 & 53 & 2 & 0 & 0 \\
\hline 111572 & 1000000 & 37 & 0 & 0 & 0 \\
\hline 111573 & 1000000 & 44 & 0 & 0 & 0 \\
\hline 111626 & 1000000 & 52 & 1 & 0 & 0 \\
\hline 111527 & 1200000 & 7 & 0 & 0 & 0 \\
\hline 111537 & 1200000 & 27 & 1 & 0 & 1000 \\
\hline 111539 & 1200000 & 20 & 0 & 0 & 0 \\
\hline 111540 & 1200000 & 28 & 0 & 0 & 0 \\
\hline 111541 & 1200000 & 32 & 0 & 0 & 0 \\
\hline 111551 & 1200000 & 47 & 3 & 0 & 0 \\
\hline 111552 & 1200000 & 18 & 1 & 0 & 1000 \\
\hline 111560 & 1200000 & 38 & 0 & 0 & 0 \\
\hline 111561 & 1200000 & 11 & 0 & 0 & 0 \\
\hline 111562 & 1200000 & 14 & 0 & 0 & 0 \\
\hline 111569 & 1200000 & 52 & 2 & 0 & 0 \\
\hline 111570 & 1200000 & 1 & 0 & 0 & 0 \\
\hline 111571 & 1200000 & 42 & 0 & 0 & 0 \\
\hline 111530 & 1350000 & 31 & 0 & 0 & 0 \\
\hline 111536 & 1350000 & 43 & 2 & 1 & 0 \\
\hline 111547 & 1350000 & 23 & 0 & 0 & 0 \\
\hline 111550 & 1350000 & 46 & 2 & 0 & 0 \\
\hline 111556 & 1350000 & 6 & 0 & 0 & 1000 \\
\hline 111566 & 1350000 & 50 & 4 & 1 & 0 \\
\hline 111574 & 1350000 & 25 & 2 & 0 & 1000 \\
\hline 111568 & 1600000 & 19 & 0 & 0 & 1000 \\
\hline 111545 & 1800000 & 48 & 1 & 0 & 0 \\
\hline 111534 & 2000000 & 21 & 0 & 0 & 1000 \\
\hline 111542 & 2000000 & 49 & 1 & 0 & 2000 \\
\hline 111559 & 2000000 & 16 & 0 & 0 & 3000 \\
\hline
\end{tabular}

Batasan nilai pada kriteria yang digunakan disajikan pada tabel 5. 
Tabel 5. Batasan nilai kriteria

\begin{tabular}{llccccc}
\hline No & \multicolumn{1}{c}{ Kriteria } & Min & Max & \multicolumn{3}{c}{ Kategori } \\
\hline 1 & Penghasilan Wali Murid & 800.000 & 1.500 .000 & Sedikit & Sedang & Banyak \\
2 & Peringkat Kelas & 5 & 15 & Baik & Sedang & Buruk \\
3 & Ketidakhadiran & 2 & 8 & Sedikit & Sedang & Banyak \\
4 & Catatan BP & 1 & 5 & Sedikit & Sedang & Banyak \\
5 & Uang Saku & 5000 & 50.000 & Sedikit & Sedang & Banyak \\
\hline
\end{tabular}

Berdasarkan tabel batasan nilai kriteria diatas, maka dapat dibuat suatu rumus untuk menentukan derajat keanggotaan masing-masing variabel yaitu variabel penghasilan wali murid kategori sedikit menggunakan persamaan 10 atau 11 atau 12, kategori sedang menggunakan persamaan 13 atau 14 atau 15, kategori banyak menggunakan persamaan 16 atau 17 atau 18. Variabel peringkat kelas kategori baik menggunakan persamaan 19 atau 20 atau 21, kategori sedang menggunakan persamaan 22 atau 23 atau 24, kategori buruk menggunakan persamaan 25 atau 26 atau 27. Variabel ketidakhadiran kategori sedikit menggunakan persamaan 28 atau 29 atau 30, kategori sedang menggunakan persamaan 31 atau 32 atau 33, kategori banyak menggunakan persamaan 34 atau 35 atau 36. Variabel catatan BP kategori sedikit menggunakan persamaan 37 atau 38 atau 39, kategori sedang menggunakan persamaan 40 atau 41 atau 42, kategori banyak menggunakan persamaan 43 atau 44 atau 45 . Variabel uang saku kategori sedikit menggunakan persamaan 46 atau 47 atau 48, kategori sedang menggunakan persamaan 49 atau 50 atau 51, kategori banyak menggunakan persamaan 52 atau 53 atau 54. Penggunaan "atau" dimaksudkan disesuaikan dengan nilai data (x), misal jika data penghasilan wali murid adalah 800.000, maka nilai derajat keanggotaan kategori sedikit menggunakan persamaan 4 dan didapat nilai derajat keanggotaan 1.

\begin{tabular}{|c|c|c|c|}
\hline$\mu$ Sedikit $[\mathrm{x}]$ & $\left\{\begin{array}{c}1 \\
0\end{array}\right.$ & $\begin{array}{l}x<800.000 \\
800.000 \leq x \leq 1.500 .000 \\
x>1.500 .000\end{array}$ & $\begin{array}{l}(10) \\
(11) \\
(12)\end{array}$ \\
\hline$\mu$ Sedang $[\mathrm{x}]$ & $\left\{\begin{array}{r}0 \\
(x-1.150 .00 \\
(1.500 .00-x\end{array}\right.$ & $\begin{array}{cc} & x<800.000 \text { atau } x>1.500 .000 \\
0.000 & 800.000 \leq x \leq 1.150 .000 \\
0.000 & 1.150 .000 \leq x \leq 1.500 .000\end{array}$ & $\begin{array}{l}(13) \\
(14) \\
(15)\end{array}$ \\
\hline$\mu$ Banyak $[\mathrm{x}]$ & $\left\{\begin{array}{r}0 \\
(x-1.150 .00 \\
1\end{array}\right.$ & $\begin{array}{l}x \leq 1.500 .000 \\
1.150 .000 \leq x \leq 1.500 .000 \\
x>1.500 .000\end{array}$ & $\begin{array}{l}(16) \\
(17) \\
(18)\end{array}$ \\
\hline$\mu$ Baik $[\mathrm{x}]\}$ & $\begin{array}{c}1 \\
(5-x) / 10 \\
0\end{array}$ & $\begin{array}{l}x<5 \\
5 \leq x \leq 15 \\
x>10\end{array}$ & $\begin{array}{l}(19) \\
(20) \\
(21)\end{array}$ \\
\hline$\mu$ Sedang $[\mathrm{x}]$ & $\left\{\begin{array}{c}0 \\
(x-10) / 10 \\
(15-x) / 5\end{array}\right.$ & $\begin{array}{c}x<5 \text { atau } x>15 \\
5 \leq x \leq 15 \\
10 \leq x \leq 15\end{array}$ & $\begin{array}{l}(22) \\
(23) \\
(24)\end{array}$ \\
\hline$\mu$ Buruk $[\mathrm{x}]$ & $\left(\begin{array}{c}0 \\
(x-10) / 5 \\
1\end{array}\right.$ & $\begin{array}{l}x \leq 10 \\
10 \leq x \leq 15 \\
x>15\end{array}$ & $\begin{array}{l}(25) \\
(26) \\
(27)\end{array}$ \\
\hline$\mu$ Sedikit $[\mathrm{x}]$ & $\left\{\begin{array}{c}1 \\
(2-x) / 5 \\
0\end{array}\right.$ & $\begin{array}{l}x<2 \\
\quad 2 \leq x \leq 8 \\
x>8\end{array}$ & $\begin{array}{l}(28) \\
(29) \\
(30)\end{array}$ \\
\hline$\mu$ Sedang $[\mathrm{x}]$ & $\left\{\begin{array}{c}0 \\
(x-5) / 6 \\
(8-x) / 3\end{array}\right.$ & $\begin{array}{c}x<2 \text { atau } x>8 \\
2 \leq x \leq 5 \\
5 \leq x \leq 8\end{array}$ & $\begin{array}{l}(31) \\
(32) \\
(33)\end{array}$ \\
\hline$\mu$ Banyak $[\mathrm{x}]$ & $\left\{\begin{array}{c}0 \\
(5-x) / 3 \\
1\end{array}\right.$ & $\begin{array}{l}x \leq 5 \\
\quad 5 \leq x \leq 8 \\
x>8\end{array}$ & $\begin{array}{l}(34) \\
(35) \\
(36)\end{array}$ \\
\hline
\end{tabular}


$\mu$ Sedikit $[x]\left\{\begin{array}{c}1 \\ (1-x) / 4 \\ 0\end{array}\right.$

$\mu$ Sedang $[\mathrm{x}]\left\{\begin{array}{c}0 \\ (\mathrm{x}-3) / 4 \\ (5-x) / 2\end{array}\right.$

$\mu$ Banyak $[\mathrm{x}]\left\{\begin{array}{c}0 \\ (\mathrm{x}-4) / 2 \\ 1\end{array}\right.$

$\mu$ Sedikit $[\mathrm{x}]\left\{\begin{array}{c}1 \\ (5000-\mathrm{x}) / 45.000 \\ 0\end{array}\right.$

$\mu$ Sedang $[\mathrm{x}]\left\{\begin{array}{c}0 \\ (\mathrm{x}-27.500) / 45.000 \\ (5.000-x) / 22.500\end{array}\right.$

$\mu$ Banyak $[x]\left\{\begin{array}{c}0 \\ (x-27.500) / 22.500 \\ 1\end{array}\right.$ $x<1$

$1 \leq x \leq 5$

$x>5$

$x<1$ atau $x>5$

$1 \leq x \leq 4$

$4 \leq x \leq 5$

$x \leq 3$

$x>5$

\section{HASIL DAN PEMBAHASAN}

Pada tahap pengujian, menggunakan kriteria pengujian yang bersifat samar seperti tersaji pada tabel 5 .

Tabel 5. Nilai kriteria pengujian

\begin{tabular}{cccc}
\hline No & Kode & Kriteria & Kategori \\
\hline 1 & K1 & Penghasilan Wali Murid & Sedikit \\
2 & K2 & Peringkat Kelas & Baik \\
3 & K3 & Ketidakhadiran & Sedikit \\
4 & K4 & Catatan BP & Sedikit \\
5 & K5 & Uang Saku & Sedikit \\
\hline
\end{tabular}

Penggolahan data siswa untuk menyajikan informasi siapa yang memiliki jumlah nilai kategori lebih tinggi pada masing-masing kriteria dilakukan dengan mengimplementasikan persamaan-persamaan 4 sampai dengan persamaan 48 yang sesuai dengan kondisi data pada query serta ditambahkan fungsi pengurutan data hasil penjumlahan dari yang terbesar ke yang terkecil. Didapat hasil seperti tersaji pada tabel 6 sebagai berikut :

Tabel 6. Hasil uji coba

\begin{tabular}{ccccccc}
\hline \multirow{2}{*}{$\boldsymbol{N I S}$} & \multicolumn{5}{c}{ Kriteria } & \multirow{2}{*}{ Hasil } \\
\cline { 2 - 5 } 111570 & 0.57 & 1 & 1 & 1 & 1 & 4.57 \\
111562 & 0.57 & 0.9 & 1 & 1 & 1 & 4.47 \\
111525 & 0.29 & 1 & 1 & 1 & 1 & 4.29 \\
111538 & 0.29 & 1 & 1 & 1 & 1 & 4.29 \\
111554 & 0.29 & 1 & 1 & 1 & 1 & 4.29 \\
111561 & 0.57 & 0.6 & 1 & 1 & 1 & 4.17 \\
111544 & 0.29 & 0.8 & 1 & 1 & 1 & 4.09 \\
111535 & 0 & 1 & 1 & 1 & 1 & 4 \\
111555 & 0.29 & 0.7 & 1 & 1 & 1 & 3.99 \\
111556 & 0.79 & 0.1 & 1 & 1 & 1 & 3.89 \\
111529 & 0.29 & 0.5 & 1 & 1 & 1 & 3.79 \\
111530 & 0.79 & 0 & 1 & 1 & 1 & 3.79 \\
111547 & 0.79 & 0 & 1 & 1 & 1 & 3.79 \\
111527 & 0.57 & 0.2 & 1 & 1 & 1 & 3.77 \\
111533 & 0.29 & 0.4 & 1 & 1 & 1 & 3.69 \\
\hline
\end{tabular}




\begin{tabular}{|c|c|c|c|c|c|c|}
\hline \multirow{2}{*}{$N I S$} & \multicolumn{5}{|c|}{ Kriteria } & \multirow{2}{*}{ Hasil } \\
\hline & $K 1$ & $K 2$ & K3 & K4 & K5 & \\
\hline 111563 & 0.29 & 0.3 & 1 & 1 & 1 & 3.59 \\
\hline 111537 & 0.57 & 0 & 1 & 1 & 1 & 3.57 \\
\hline 111539 & 0.57 & 0 & 1 & 1 & 1 & 3.57 \\
\hline 111540 & 0.57 & 0 & 1 & 1 & 1 & 3.57 \\
\hline 111541 & 0.57 & 0 & 1 & 1 & 1 & 3.57 \\
\hline 111552 & 0.57 & 0 & 1 & 1 & 1 & 3.57 \\
\hline 111560 & 0.57 & 0 & 1 & 1 & 1 & 3.57 \\
\hline 111571 & 0.57 & 0 & 1 & 1 & 1 & 3.57 \\
\hline 111027 & 0.29 & 0 & 1 & 1 & 1 & 3.29 \\
\hline 111526 & 0.29 & 0 & 1 & 1 & 1 & 3.29 \\
\hline 111528 & 0.29 & 0 & 1 & 1 & 1 & 3.29 \\
\hline 111531 & 0.29 & 0 & 1 & 1 & 1 & 3.29 \\
\hline 111532 & 0.29 & 0 & 1 & 1 & 1 & 3.29 \\
\hline 111543 & 0.29 & 0 & 1 & 1 & 1 & 3.29 \\
\hline 111546 & 0.29 & 0 & 1 & 1 & 1 & 3.29 \\
\hline 111548 & 0.29 & 0 & 1 & 1 & 1 & 3.29 \\
\hline 111549 & 0.29 & 0 & 1 & 1 & 1 & 3.29 \\
\hline 111553 & 0.29 & 0 & 1 & 1 & 1 & 3.29 \\
\hline 111557 & 0.29 & 0 & 1 & 1 & 1 & 3.29 \\
\hline 111558 & 0.29 & 0 & 1 & 1 & 1 & 3.29 \\
\hline 111564 & 0.29 & 0 & 1 & 1 & 1 & 3.29 \\
\hline 111565 & 0.29 & 0 & 1 & 1 & 1 & 3.29 \\
\hline 111572 & 0.29 & 0 & 1 & 1 & 1 & 3.29 \\
\hline 111573 & 0.29 & 0 & 1 & 1 & 1 & 3.29 \\
\hline 111626 & 0.29 & 0 & 1 & 1 & 1 & 3.29 \\
\hline 111534 & 0 & 0 & 1 & 1 & 1 & 3 \\
\hline 111542 & 0 & 0 & 1 & 1 & 1 & 3 \\
\hline 111545 & 0 & 0 & 1 & 1 & 1 & 3 \\
\hline 111559 & 0 & 0 & 1 & 1 & 1 & 3 \\
\hline 111568 & 0 & 0 & 1 & 1 & 1 & 3 \\
\hline 111550 & 0.79 & 0 & 0 & 1 & 1 & 2.79 \\
\hline 111574 & 0.79 & 0 & 0 & 1 & 1 & 2.79 \\
\hline 111551 & 0.57 & 0 & 0.17 & 1 & 1 & 2.74 \\
\hline 111569 & 0.57 & 0 & 0 & 1 & 1 & 2.57 \\
\hline 111567 & 0.29 & 0 & 0 & 1 & 1 & 2.29 \\
\hline 111566 & 0.79 & 0 & 0.33 & 0 & 1 & 2.12 \\
\hline 111536 & 0.79 & 0 & 0 & 0 & 1 & 1.79 \\
\hline
\end{tabular}

Dari hasil pengujian yang dilakukan, dengan kriteria nilai penghasilan wali murid yang sedikit, peringkat kelas yang baik, Ketidakhadiran sedikit, catatan BP yang sedikit dan uang saku yang sedikit siswa dengan NIS 111570 memiliki nilai perhitungan yang lebih tinggi yaitu 4,57 dan dijadikan sebagai urutan pertama. Tampilan program untuk proses penghitungan disajikan pada gambar 5. Sedangkan contoh hasil penyeleksian dengan menampilkan 5 nilai teratas disajikan pada gambar 6 . 


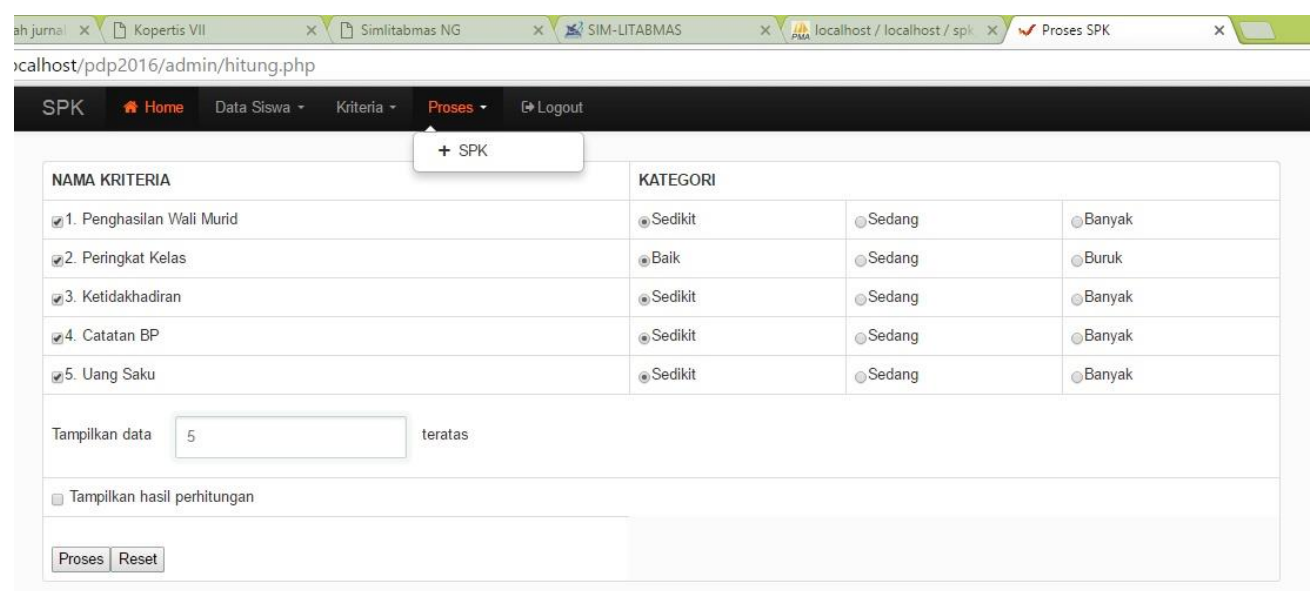

Gambar 5. Screenshoot Aplikasi

DATA HASIL SELEKSI 5 DATA TERATAS

\begin{tabular}{|r|c|l|c|c|}
\hline NO & \multicolumn{1}{|c|}{ NIS } & \multicolumn{1}{|c|}{ NAMA SISWA } & KELAS & NILAI \\
\hline 1 & 111570 & JONNY DWISERA LAKSANA & 1 TKJ1 & 4.56999999284744 \\
\hline 2 & 111562 & FREMA TRI WIDYA PUTRA & 1 TKJ1 & 4.46999996900558 \\
\hline 3 & 111538 & ARJUN CAHYO W & 1 TKJ1 & 4.28999999165535 \\
\hline 4 & 111525 & ADE SUPRIYATNA & 1 TKJ1 & 4.28999999165535 \\
\hline 5 & 111554 & EBY ASDIANTORO & 1 TKJ1 & 4.28999999165535 \\
\hline
\end{tabular}

Gambar 6. Screenshot Hasil Seleksi Dengan 5 Nilai Teratas

\section{KESIMPULAN}

Berdasarkan dari percobaan yang dilakukan, maka dapat disimpulkan bahwa telah berhasil dibuat sistem informasi penentu calon penerima beasiswa menggunakan metode fuzzy database model Tahani. Dengan menggunakan sistem ini, dapat langsung diketahui urutan-urutan yang dapat dijadikan pertimbangan prioritas dalam penentuan calon penerima beasiswa.

\section{DAFTAR PUSTAKA}

[1] Elmasri., Ramez dan Navathe., Shamkant B. 2000. Fundamentals of Database System, https://ia700601.us.archive.org/11/items/FundamentalsOfDatabaseSystemselmasrinavathe/Fundame ntalsOfDatabaseSystemselmasrinavathe.pdf. Diunduh 20 Januari 2015.

[2] Kusrini. (2007). Konsep dan Aplikasi Sistem Pendukung Keputusan. Andi Yogyakarta

[3] Nugroho, B. (2004). Database Relasional dengan MySQL. Andi Yogyakarta

[4] Kusumadewi, S dan Purnomo H. (2004). Aplikasi Logika Fuzzy untuk Pendukung Keputusan. Yogyakarta. Graha Ilmu.

[5] Akmal, Indah, N. 2014. " Sistem Pendukung Keputusan Penentuan Pemilihan Laptop Dengan Menerapkan Fuzzy Tahani”. Jurnal Pelita Informatika Budi Darma, Volume IV Nomor 1, Maret 2014, ISSN : 2301-9425.

[6] Hamdani. Haviluddin. Abdillah, M, S. 2011. "Sistem Pendukung Keputusan Pembelian Notebook Menggunakan Logika Fuzzy Tahani”. Jurnal Informatika Mulawarman, Volume 6 Nomor 3, September 2011, Hal 98-104.

[7] Widodo, Sulistyo. Utomo, Victor, G. 2014. “ Rancang Bangun Aplikasi Travel Recommender Berbasis WAP Menggunakan Metode Fuzzy Model Tahani”. Jurnal Teknologi Informasi dan Komunikasi, Volume 5 Nomor 1, Maret 2014, ISSN : 2087-0868.

[8] Uyun, S. 2009. "Aplikasi Basisdata Fussy Berbasis Web Untuk Pemilihan Handphone". Jurnal Kursor, Volume 5, Nomor 1, Januari 2009, ISSN: 0216-0544

[9] Eliyani. Utomo Pujianto. Didin Rosyadi. 2009. "Decision Support System Untuk Pembelian Mobil Menggunakan Fuzzy Database Model Tahani”. SNATI 2009, ISSN: 1907-5022 